\title{
MARKETING RESOURCE RICHNESS AND MARKETING SURVIVAL OF AUTO PARTS BUSINESSES IN THAILAND
}

Nattawut Panya, Mahasarakham Business School, Mahasarakham University, Thailand Phapruke Ussahawanitchakit, Mahasarakham Business School, Mahasarakham University, Thailand

\author{
dx.doi.org/10.18374/IJBR-13-3.7
}

\begin{abstract}
This study aims to evaluate the capability of firms that implement marketing resources into resource allocation effectiveness. Marketing resource richness consists of customer- linking capability, market innovation capability, human resources asset and reputation assets. In addition, this also investigates the relationship between its antecedents and consequences by using competitive learning as a moderator. The results were derived from a survey of 136 auto parts firms in Thailand. The results show that human resources asset, market innovation capability, customer-linking capability, and reputation asset have an important positive effect on marketing survival. In addition, market experience, market munificence, market vision, and employee knowledge positively relate to marketing resource richness. However, competitive learning has no effect on the relationship between market resource richness and its antecedents. Theoretical and managerial contributions are provided. A conclusion, suggestions, and directions for future research are also highlighted.
\end{abstract}

Keywords: Marketing Resource Richness, Product Innovation Diversity, Customer Value Creation, Marketing Risk Reduction, Best Marketing Practice, Market Vision, Employee Knowledge, Marketing Experience, Market Munificence, Competitive Learning, Marketing Survival 